\title{
Osteopathic Treatment of Patients Suffering from Chronic Non-specific Low Back Pain: A Dose- response Pilot Study
}

\section{Espen Glomsrød $^{1 *}$, Stig Larsen ${ }^{2}$ and Roar Jensen ${ }^{2,3}$}

${ }^{1}$ Department of of Global Health and Primary Care, University of Bergen Norway

${ }^{2}$ Professor in controlled clinical research methodology and statistics, Faculty of veterinary medicine, University of Life Sciences Oslo, Norway ${ }^{3}$ Physiotherapy research Group, Department of Global Health and Primary Care, University of Bergen Norway

\section{Abstract}

Background: Dose- response studies are needed for pharmaceuticals, but have not been commonly performed in the field of manual therapy.

Objective: The aim of this study was to determine the combination of treatment numbers and intervals needed to obtain the optimal effect of osteopathic treatment for patients with chronic non-specific low back pain and to highlight methodological aspects concerning dose-response studies in the field of manual therapies.

Design: The study was performed as an open, randomized, single -centre trial with a 22 factorial design. Methods: The patients were allocated equally to four groups by block randomization. The first group was given two treatments at an interval of 14 days, the second group was given two treatments at an interval of seven days, the third group received four treatments with intervals of 14 days, and the fourth group received four treatments with intervals of seven days. Oswestry Disability Index (ODI) and the Numeric Pain Rating Scale (NPRS) were recorded at baseline and two weeks post treatment.

Participants: Eight women and four men with chronic non-specific low back pain were included.

Results: The two treatments with an interval of 14 days resulted in an ODI reduction of only 1.3 (95\% CI: $-21-24.1)$. The largest reduction in ODI was detected in the four treatments with the seven days intervals. The mean reduction in this group was found to be 19.3 (95\% CI: -14.4 - 53.1). An interaction between the number of treatments and the treatment interval was observed.

Conclusion: The effect increased with increases in the numbers of treatment and reductions in the treatment interval. The program with four treatments and intervals of seven days was found to be optimal among the four examined regimens.

\section{Introduction}

Low back pain (LBP) represents a substantial problem in society today. This non-lethal health problem is among the most expensive in terms of social security, short time sick leave, loss of productivity, and the use of health care services [1]. The quantity of research with the aim of identifying treatment modalities with satisfactory efficacy and effectiveness is been substantial. Based on the existing research results, guidelines for the treatment of low back pain have been developed in Europe, both for chronic nonspecific LBP [2] and acute nonspecific LBP [3]. Norwegian guidelines for the treatment of LBP were published in 2002 and revised in 2007 [1]. These guidelines recommend manipulation as a treatment modality for sub-acute LBP in combination with examination and advice from specialists, exercise, massage and injections. For chronic nonspecific LBP, manipulation is recommended to a moderate degree on the same level as other modalities for pain reduction and functional improvement Rubenstein et al. [4] concluded that there are no documented differences between the effects of manipulation/mobilization and the effects of other forms of intervention for patients with chronic LBP. This review of 26 randomized controlled trials (RCTs) including 6070 patients examined treatments given by chiropractors, physiotherapists, and osteopaths.

Few published studies have established the maximum tolerated dose (MTD) or minimum effective dose (MED) of manual therapy, chiropractic care and osteopathy. Haas, Groupp and Kraemer [5] performed a pilot study to illuminate the effects of chiropractic care in terms of the numbers of treatments required. This study concluded that there was a positive, clinically important effect of the number of E-mail: eglom@halden.net org/10.15344/2016/ijccp/115 original author and source are credited.

\section{Publication History:}

Received: May 29, 2016 Accepted: July 27, 2016

Published: July 29, 2016

\section{Keywords:}

Low-back pain, Dose effect, Factorial design, Osteopathic therapy disability after four weeks. The relief was substantial for the patients who received care three to four times per week over a period of three weeks. A full-scale follow up trial of the optimal number of visits to a chiropractor for spinal manipulation for chronic LBP concluded that 12 visits yielded the most favourable results [6].

Haas, Groupp, Aickin et al. [7] performed a study to acquire information to design a clinical trial, determine its feasibility, and make preliminary estimates of the relationship between headache outcomes and the number of chiropractor treatments. The results indicated that larger clinical trials were needed to study the relationship between pain relief and the number of chiropractic treatments. However, the study indicated that nine to 12 of chiropractic care treatments are needed for the treatment of cervicogenic headache.

Haas et al. [8] later published the results from another prospective RCT that included 80 patients who suffered from cervicogenic headache. This study detected a plateau in the effects of intervention effect after eight to 16 treatments. Recently, a prospective single

"Corresponding Author: Dr. Espen Glomsrød, Department of of Global Health and Primary Care, University of Bergen, Stigveien 16, 1785 Halden, Norway;

Citation: Glomsrød E, Larsen S, Jensen R (2016) Osteopathic Treatment of Patients Suffering from Chronic Non-specific Low Back Pain: A Dose- response Pilot Study. Int J Clin Pharmacol Pharmacother 1: 115. doi: http://dx.doi.

Copyright: () 2016 Glomsrød et al. This is an open-access article distributed under the terms of the Creative Commons Attribution License, which permits unrestricted use, distribution, and reproduction in any medium, provided the 
Citation: Glomsrød E, Larsen S, Jensen R (2016) Osteopathic Treatment of Patients Suffering from Chronic Non-specific Low Back Pain: A Dose- response Pilot Study. Int J Clin Pharmacol Pharmacother 1: 115. doi: http://dx.doi.org/10.15344/2016/ijccp/115

Page 2 of 5

blinded placebo controlled RCT assessing the effectiveness of spinal manipulation therapy (SMT) in chronic nonspecific LBP was published [9]. The study concluded that 12 SMT treatments in a one month period is effective in the treatment of chronic nonspecific LPB. To obtain long-term benefits, maintenance SMT after the initial intensive manipulation therapy is recommended. To study the effects and dose-response relationship of chiropractic treatments that combine ischemic compression and spinal manipulation on reductions in pain intensity, sleep disturbance, and fatigue, 15 female patients with fibromyalgia were given 30 chiropractic treatments [10]. A significant decrease in pain intensity, an increase in the quality of sleep, and improved fatigue levels were observed after 15 treatments. No significant changes were observed between the last treatment and the one month follow-up assessment.

Dose-response studies of pharmaceuticals aim to determine the daily dosages that correspond to the MED and MTD and also include the duration of the treatment. A few dose-response studies of manual therapy that focus exclusively on the number of treatments needed to establish an effect has been performed. However, the duration between each treatment might be an important aspect of the dosage. To the best of our knowledge, the between-treatment interval has not previously been included in any manual therapy dose-response study.

The aim of this study was to estimate the combination of the number of treatments and the treatment interval that elicits the optimal effects of osteopathic treatment for patients with chronic non-specific low back pain and to highlight methodological aspects concerning doseresponse studies in the field of manual therapies.

\section{Materials and Methods}

The reference population consisted of patients of both genders between the ages of 18 and 67 years who suffered from chronic nonspecific LBP. LBP was defined as pain in the area below the twelfth rib and above the gluteal fold with or without pain radiating to the lower extremities. Nonspecific pain indicates pain without a known pathoanatomic cause that possibly originated from the muscles, joints, and intervertebral discs. Chronic pain was defined as pain with a duration of at least twelve weeks [1]

Study population: The patients in the reference population who fulfilled at least one of the following criteria were excluded from the study population: pain that was perceived as different from previous pain, constant pain, pain that increased over time, pain during rest, nausea, fever and/or weight loss, trauma, tumour, use of steroids or immunosuppressants, drug abuse, widespread neurological problems, deformities of the vertebral column, increased sedimentation rate, severe morning stiffness with a duration of more than one hour, visceral diseases, symptoms of cauda equine syndrome,loss of sensibility/paresis in the perineum, retention/leakage of urine, decreased sphincter tone, pathological sacral reflexes, progressive paresis, paralyses, people who were not able to express themselves in the Norwegian language and people who were psychological unstable.

Study sample: A total of 8 women and 4 men with a mean age of 55.8 years (range 24 to 62 ) and a mean body mass index (BMI) of $26.0 \mathrm{~kg} /$ $\mathrm{m}^{2}$ (range 22.5 to 30,1 ) were included in the study. The patients were equally allocated into four treatment groups of three patients each. The four treatment groups were found to be clinically equal regarding distributions of all of the observed patient characteristics (Table 1).

\begin{tabular}{|l|l|l|l|l|}
\hline Factor & \multicolumn{2}{|l|}{ Number of treatments } & \multicolumn{2}{l|}{ Treatment intervals } \\
\hline & 2 treatments & 4 treatments & 7 Days & 14 Days \\
\hline Age (Years) & $44.3(15.3)$ & $\begin{array}{l}47.2(12.1) \\
24 \text { to } 62\end{array}$ & $\begin{array}{l}46.8(10.8) \\
27 \text { to } 60\end{array}$ & $\begin{array}{l}44.7(16.3) \\
24 \text { to } 62\end{array}$ \\
\hline Weight $(\mathrm{Kg})$ & $80.3(6.9)$ & $74.8(9.6)$ & $76.5(9.3)$ & $78.7(8.4)$ \\
& 74 to 90 & 65 to 87 & 66 to 90 & 65 to 87 \\
\hline Height $(\mathrm{cm})$ & $172(7.7)$ & $173(4.9)$ & $170(5.4)$ & $176(5.6)$ \\
& 162 to 182 & 168 to 180 & 162 to 178 & 168 to 182 \\
\hline BMI Kg/m 2 & $27.1(1.1)$ & $25,0(3.1)$ & $26.6(3.0)$ & $25.4(1.9)$ \\
& 26.0 to 28.6 & 22.5 to 30.1 & 22.8 to 30.1 & 22.5 to 27.5 \\
\hline
\end{tabular}

Table 1: Distributions of age, weight, height and body-mass Index (BMI) for the entire group and each subgroup. The results are expressed as mean values with the SDs in brackets and the total ranges.

Recruitment of patients: The patients were recruited from three general practitioners (GPs) in Halden, Norway. The patients who fulfilled the criteria for inclusion were asked to participate in the study by these GPs. The patients were given oral information about the study from their GP, and those who were interested in participating were given additional written information. The patients who were willing to provide informed consent for participation were asked to contact the study manager.

Study design: The study was performed as an open, randomized, single centre study with a 22 factorial design (Figure 1). The two factors included were the "number of treatments" and the "treatment interval" in days. The number of treatments used in the study were two and four and the treatment interval were seven and 14 days. The patients were allocated to one of the four treatment groups by block randomization with a fixed block size of four.

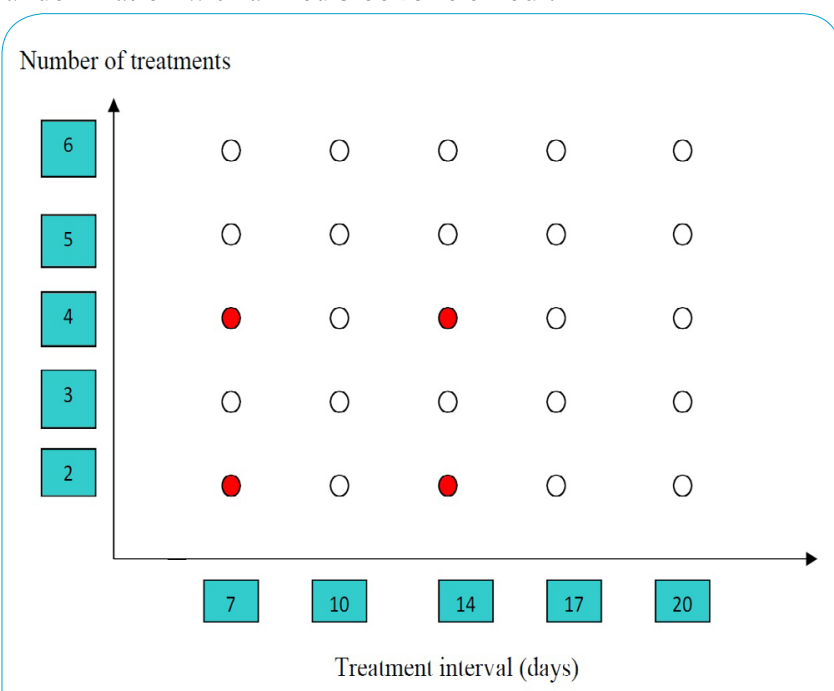

Figure 1: $\mathrm{n}^{2}$ factorial design illustrated with $\mathrm{n}=5$. The filled points illustrate the studied treatment group in the $2^{2}$ design.

Study procedure: The 12 patients were instructed to avoid all other forms of LBP care outside the study protocol during the time of the study, unless absolutely necessary. The medication in use was required to remain unchanged during the study period. The patients were allocated to groups that varied in the number of treatments and the treatment intervals. Six patients were allocated to receive two treatments, and six patients were allocated to receive four treatments. Each of these two groups was divided into two subgroups in which three patients had a treatment interval of seven days and three patients had a treatment interval of 14 days (Figure 2). 
Citation: Glomsrød E, Larsen S, Jensen R (2016) Osteopathic Treatment of Patients Suffering from Chronic Non-specific Low Back Pain: A Dose- response Pilot Study. Int J Clin Pharmacol Pharmacother 1: 115. doi: http://dx.doi.org/10.15344/2016/ijccp/115

Page 3 of 5

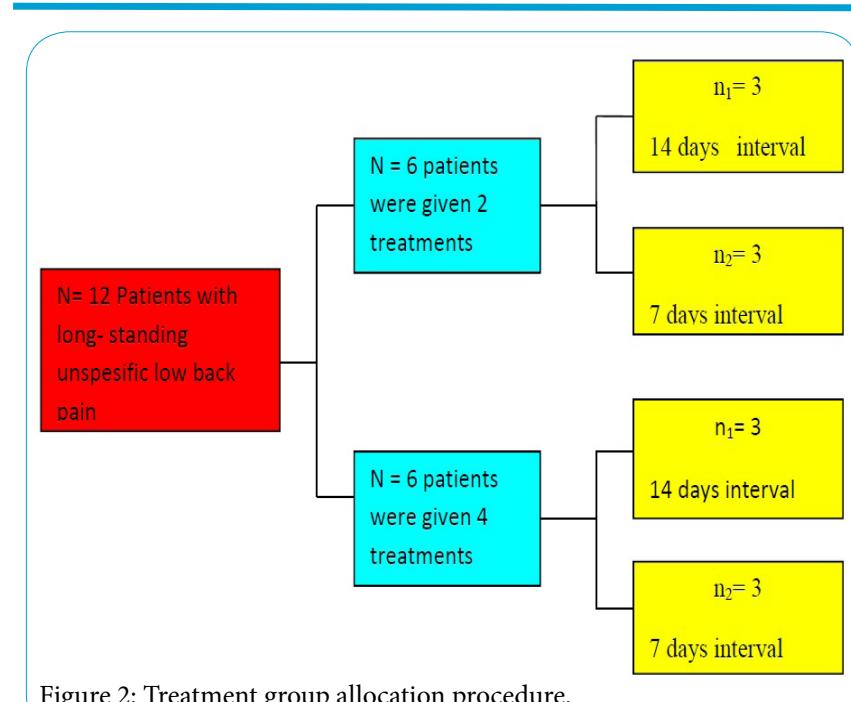

Figure 2: Treatment group allocation procedure.

The patients were all examined and treated by the same therapist. A physical examination was performed before the first treatment and included, anamneses, palpation and an orthopaedic/neurological examination. Additionally, somatic dysfunctions were recorded according to the level of importance. The first treatment was given after the examination and the patient presented for the treatment program according to the randomization. A variation of $+/-1$ day was accepted regarding the treatment interval. The patients performed the assessments before the start of treatment and two weeks after the last treatment.

Intervention: A pragmatic approach of osteopathic treatment in which all patients were treated according to their individual needs was adopted. The aim of the individual treatment was to remove the detected somatic dysfunctions and to focus on the presumed cause of the complaints and not only the putative pain producing structure. The treatment consisted of high-velocity, low-amplitude spinal manipulation (HVLA), articulatory techniques, muscle energy techniques and myofascial release techniques [11].

Assessment: The main variable of the trial was the Oswestry Disability Index (ODI) [12,13], which was used to assess daily pain and function over the last week. This index consists of more than 50 different outcomes and can be treated as a continuously distributed variable $[14,15]$. The Numeric Pain Rating Scale (NPRS) $[16,17]$ for assessing mean pain over the last week was added as a secondary variable. The ODI and the NRS-forms were recorded by the patients at baseline and at two weeks post treatment. Oral information regarding how the ODI and NPRS should be completed was provided. At the last treatment session, the patients were given the ODI and NPRS forms to fill out two weeks after treatment. All patients completed their forms as prescribed and returned them personally or by post.

The study was approved by the Norwegian Regional Ethical Comity (REK vest) under approval number 2011/1618/REK vest. All patients provided written informed consent for participation.

Statistical analyses: The primary outcome variable was the ODI, which was classified as continuously distributed and is expressed with mean values and $95 \%$ confidence intervals that were constructed with the Student procedure [18]. Categorical variables are expressed in contingency tables [19]. Both comparisons between groups and examinations of the changes within groups were performed with two- tailed tests, and differences were considered significant when the p-value was below $5 \%$. Comparisons of the groups were performed with Analyses of covariance (ANACOVA) with the baseline values as covariates [20]. Contingency table analysis was used for the categorical variables [19].

\section{Results}

The ODI score were found to be slightly higher at baseline among the patients who received two treatments compared to those who received four. Additionally, the patients allocated to the seven-day treatment intervals had slightly higher scores compared to those who were allocated to the 14 days intervals. The ODI score at baseline was found to be lower in the group who received four treatments with at an interval of 14 days compared to the other three groups.

The reduction in the ODI score from baseline to two weeks after the last treatment was influenced by both the number of treatments and the interval between treatments (Table 2). The reduction in the ODI score was to be found largest in the group receiving four treatments compared to two, and in the group with the seven days treatment interval larger compared to 14 days. The combination of the two treatments with the 14 day intervals resulted in a reduction of 1.3 (95\% CI: $-21-24.1$ ) in ODI score. This reduction increased to 5.3 (95\% CI: $-17.4-28.1$ ) by increasing the number of treatment from two to four among (Figure 3). Reducing the treatment interval from 14 to seven days while maintaining the number of treatments at two resulted in a mean reduction of 8.4 (95\% CI: $-25.4-42.1)$. The obviously largest reduction in ODI was detected in the group who received four treatments at seven-day intervals. The mean reduction in this group was found to be 19.3 (95\% CI: -14.4 - 53.1). The baseline NPRS scores of the six patients who received two treatments were found to be slightly higher than those of the patients who received four treatments, whereas the patients who were allocated to the seven day treatment intervals were similar to those allocated to the 14 day intervals. The four groups that resulted from combining the treatment intervals or the number of treatments exhibited approximately similar baseline NPRS scores.

\begin{tabular}{|l|l|c|c|}
\hline $\begin{array}{l}\text { Treatment } \\
\text { groups }\end{array}$ & Within groups & Between groups \\
\hline $\begin{array}{l}\text { Number of } \\
\text { treatments }\end{array}$ & 2 Treatments & $\begin{array}{c}4.9 \\
-8.2 \text { to } 17.9\end{array}$ & $\begin{array}{c}7.5 \\
12.3\end{array}$ \\
& 4 Treatments & -14.6 to 29.6 \\
\hline $\begin{array}{l}\text { Duration } \\
\text { between } \\
\text { treatments } \\
\text { (days) }\end{array}$ & 7 days & 13.9 & 10.5 \\
\hline Total & & -6.9 to 34.6 & -11.0 to 32.0 \\
& & 3.3 & \\
\hline
\end{tabular}

Table 2: Comparison of the reductions in Oswestry scores from baseline to two weeks post treatment. The results are expressed as mean reductions with the $95 \%$ confidence intervals.

The reductions in NPRS score from baseline to two weeks post treatment were found to be nearly equal in the groups receiving two and four treatments (Table 3). The group with treatment interval of seven days exhibited considerably greater pain reductions compared to the group with treatment interval of 14 days. Thus, the combination of four treatments at seven- day intervals was found to be superior also regarding pain reduction. 


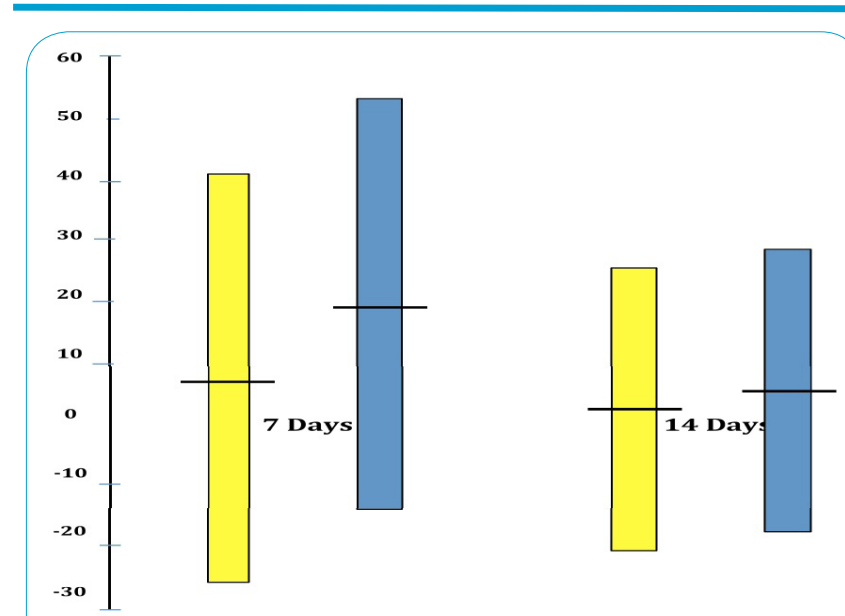

Figure 3: Reductions in Oswestry scores from baseline to two weeks post- treatment. The results are expressed as the mean values (horizontal line) with the $95 \%$ confidence intervals (bars). The two treatments are indicated as yellow colour and the four treatments are indicated as blue colour.
The treatment interval was found to have a greater influence on the treatment effect than the the number of treatments. Therefore, it is of utmost importance to examine treatment intervals shorter than seven days and intervals between seven and 14 days. The treatment intervals of seven and 14 days were selected in the present study because they were the most convenient. There are no clear indications from previous results or based on our clinical experience that support these choices. However, these intervals are not necessarily optimal. Regarding the number of treatments, it is not likely that a linear relationship exists between treatment effect and number of treatments. From a clinical perspective, there is a limit to the extent to which the treatment interval can be shortened. A plateau situation similar to those that have previously been described for the number of treatments [8] would probably not be visible in terms of treatment interval. Treatment soreness might occur one to two days after treatment [23]. Starting from a treatment interval of two days, effect might increase with increases in the interval until a maximum effect observed, and the efficacy would subsequently gradually decline. It is quite common for patients to believe that they experience better effects with shorter treatment intervals, and this factor might influence the outcome. Most probably, the maximum effect will occur at a treatment interval

\begin{tabular}{|c|c|c|c|c|c|c|c|c|c|}
\hline \multicolumn{2}{|l|}{ Subgroups } & \multicolumn{6}{|c|}{ Pain score reduction from baseline } & & \multirow{3}{*}{$\begin{array}{l}\text { Sum score } \\
14 \\
\end{array}$} \\
\hline & & \multirow{2}{*}{$\begin{array}{l}-1 \\
1 \\
\end{array}$} & \multirow{2}{*}{$\begin{array}{l}0 \\
1 \\
\end{array}$} & \multirow{2}{*}{\begin{tabular}{|l|}
1 \\
0 \\
\end{tabular}} & \multirow{2}{*}{$\begin{array}{l}2 \\
0\end{array}$} & \multirow{2}{*}{\begin{tabular}{|l|}
3 \\
1 \\
\end{tabular}} & \multirow{2}{*}{\begin{tabular}{|l|}
4 \\
3 \\
\end{tabular}} & 7 & \\
\hline Number of & 2 Treatments & & & & & & & 0 & \\
\hline Treatments & 4 Treatments & 0 & 2 & 1 & 2 & 0 & 0 & 1 & 12 \\
\hline Treatment & 7 Days & 1 & 2 & 0 & 1 & 1 & 1 & 1 & 16 \\
\hline Intervals & 14 Days & 1 & 1 & 1 & 1 & 0 & 2 & 0 & 10 \\
\hline Two treatments & /14 days interval & 1 & 0 & 0 & 0 & 0 & 2 & 0 & 7 \\
\hline Two treatments & /7 days interval & 0 & 1 & 0 & 0 & 1 & 1 & 0 & 7 \\
\hline Four treatments & /14 days interval & 0 & 1 & 1 & 1 & 0 & 0 & 0 & 3 \\
\hline \multirow[t]{2}{*}{ Four treatments } & / 7 days interval & 0 & 1 & 0 & 1 & 0 & 0 & 1 & 9 \\
\hline & & 1 & 3 & 1 & 2 & 1 & 3 & 1 & 26 \\
\hline
\end{tabular}

Table 3: Comparison of the reductions in the Numeric Pain Rating Scale scores from baseline to two weeks post- treatment. The results are expressed as the numbers of patients exhibiting each pain- score reduction and the sums of the reduction scores.

\section{Discussion}

The treatment effect expressed as the reduction in ODI score was greater with an extended number of treatments and a reduced treatment interval. This observation represented an interaction between the two factors, but the treatment interval seemed to be the dominant factor. In the present study only two treatment intervals and two treatment numbers were examined. It is not likely that there are linear relationships between the effect and the number of treatments or between the effect and the treatment intervals. A study by Haas et al. [8] indicated that the treatment effect reaches a plateau level after a certain number of treatments. Although this study covered the chiropractic treatment of neck patients, one might also find similar results regarding osteopathic treatment of chronic LBP. However, we cannot exclude the possibility that the treatment reaches its maximum effect after a certain number of treatments declines following subsequent treatments. This issue can only be resolved by investigating the effects of 5 or more treatments. It is likely that an upper limit exists regarding the number of treatments and the maximum treatment effect. To the best of our knowledge, no such study has been published. This upper limit might be related to factors such as age and the duration of LBP. It is well known that LBP varies over time [21]. The use of continuous treatment as a prophylactic aid is recommended in some cases [22]. of between two and seven days. However, it cannot be excluded that the MED for treatment interval is between seven and 14 days. These numbers were only convenient choices in the present study, and intervals greater than seven days need to be investigated.

Published studies concerning the dosage of manual intervention for chronic low back pain $[5,6]$ have concluded that patients receiving treatment three to four times per week over a period of three weeks experience substantial relief. Based on the results in these studies, the authors recommend a concentrated course of chiropractic care of up to 12 visits over three weeks. Whether the outcome of more treatments would be positive or negative remains uncertain. In this study the number of treatments and the treatment interval were absolutely dependent on each other. In the present study an obvious interaction between these two factors was observed. This knowledge of the interaction makes it more difficult to determine the optimal procedure for treatment in terms of the the two factors.

The treatment effect as expressed by reductions in NPRS did not reveal any influence of the number of treatments alone, but the effect related to treatment interval exhibited a pattern similar to that observed in the ODI scores. However, the NPRS results confirmed the interaction between the number of treatments and treatment interval and the largest reduction in the group that received four treatments at 
Citation: Glomsrød E, Larsen S, Jensen R (2016) Osteopathic Treatment of Patients Suffering from Chronic Non-specific Low Back Pain: A Dose- response Pilot Study. Int J Clin Pharmacol Pharmacother 1: 115. doi: http://dx.doi.org/10.15344/2016/ijccp/115

Page 5 of 5

seven- day intervals. This slight difference in the results between the two outcome variables might be explained by the limited number of patients within each group. With only three patients in each group, the statistical power was below $10 \%$. The present study would obviously have been strengthened by the inclusion of larger samples within each group. In contrast, the discovered pattern underlines the need for such investigations and provides a good background for further studies in this area.

The most commonly used design in dose-response studies is the factorial design. In addition to studying the effects of the included factors, factorial designs enable estimation of the interaction between the factors. Based on the obtained results, several values for the number of treatments and the treatment interval should be investigated. At least six values for each of the two factors are needed. Using a 26 factorial design results in 64 treatment groups and, if at least three patients are included in each group, a minimum of 192 patients have to be included. As previously discussed, three patients in each group produced insufficient statistical power. However, increasing the sample size in each group results in requirement for the the number of patients who are considerably higher than what is practical. One solution to this problem is to use a response surface pathway design (RSP)rather than a factorial design [24,25]. In a factorial design, each factor is treated as a categorical variable with fixed values, whereas each factor is treated as a continuous variable in RSP designs. Based on the present study and the available studies, it seems that the number of treatments have to be between two and $12[5,6]$, and the treatment interval should be between two and 14 days. Such a study based on a three-level between-patient RSP design would require only 15 patients and a four-level design increases the required patient number to 24 .

\section{Conclusion}

The effect of treatment was determined to increase with increases in the number of treatments and reductions in the treatment interval. Four treatments at intervals of seven days were found to be superior among the four examined regimens. The use of RSP- design should be considered in further studies in this field.

\section{Competing Interest}

The authors declare that they have no competing interests.

\section{Author Contributions}

EG conceived the study, performed the data collection and wrote the first draft of the manuscript. SL contributed to the design of the study and analysed the data. RJ contributed to the planning of the research. All authors have approved the final version of the manuscript.

\section{References}

1. Lærum E, red., redaktør. Nasjonale kliniske retningslinjer Korsryggsmerter med og uten nerverotutstråling. Formi Formidlingsenheten for muskel- og skjelettlidelser Sosial- og helsedirektoratet; 2007.

2. Airaksinen O, Brox JI, Cedraschi C, Hildebrandt J, Klaber-Moffett J, et al (2006) Chapter 4. European guidelines for the management of chronic nonspecific low back pain. Eur Spine J 2: S192-S300.

3. Van Tulder M, Becker A, Bekkering T, Breen A, del Real MTG, et al. (2006) Chapter 3. European guidelines for the management of acute nonspecific low back pain in primary care. Eur Spine J 2: S169-S191.

4. Rubinstein SM, van Middelkoop M, Assendelft WJJ, de Boer MR, van Tulder MW (2011) Spinal manipulative therapy for chronic low-back pain: an update of a Cochrane review. Spine (Phila Pa 1976) 36: E825-E846.
5. Haas M, Groupp E, Kraemer DF (2004) Dose-response for chiropractic care of chronic low back pain. Spine J 4: 574-583.

6. Haas M, Vavrek D, Peterson D, Polissar N, Neradilek M (2014) Doseresponse and efficacy of spinal manipulation for care of chronic low back pain: a randomized controlled trial. Spine J 14: 1106-1116.

7. Haas M, Groupp E, Aickin M, Fairweather A, Ganger B, et al. (2004) Dose response for chiropractic care of chronic cervicogenic headache and associated neck pain: a randomized pilot study. J Manipulative Physio Ther desember 27: 547-553.

8. Haas M, Spegman A, Peterson D, Aickin M, Vavrek D (2010) Dose response and efficacy of spinal manipulation for chronic cervicogenic headache: a pilot randomized controlled trial. Spine J 10: 117.

9. Senna MK, Machaly SA (2011) Does maintained spinal manipulation therapy for chronic nonspecific low back pain result in better long-term outcome? Spine (Phila Pa 1976) 36: 1427-1437.

10. Hains G, Hains F (2000) A combined ischemic compression and spinal manipulation in the treatment of fibromyalgia: a preliminary estimate of dose and efficacy. J Manipulative Physiol Ther M 23: 225-230.

11. De Stefano L (2011) Greenman`s principles of Manual Medicine. (4th edn). Philadelphia: Wolters Kluwer Lippicott Williams\& Wilkins.

12. Kopec JA (2000) Measuring functional outcomes in persons with back pain a review of backspecific questionnaires. Spine (Phila Pa 1976) 25: 31103114.

13. Grotle M, Brox JI, Vøllestad NK (2005) Functional status and disability questionnaires: what do they assess? A systematic review of back-specific outcome questionnaires. Spine (Phila Pa 1976) 30: 130-40.

14. Fenstad G, Walløe L, Wille S (1977) Three tests for regression compared by stochastic simulation under normal and heavy tailed distribution of errors. Scand J Stat 4: 31- 34

15. Fenstad G, Kjærnes M, Walløe L (1980) Robust estimation of standard deviation. J Stat Comput Simul 10: 113-132.

16. Von Korff M, Jensen MP, Karoly P (2000) Assessing global pain severity by self-report in clinical and health services research. Spine (Phila Pa 1976) 25: 3140-3151.

17. Grotle M, Brox JI, Vøllestad NK (2004) Concurrent comparison of responsiveness in pain and functional status measurements used for patients with low back pain. Spine (Phila Pa 1976) 29: E492-E501.

18. Altman DG (2002) Practical statistics in Medical Research. 2nd ed Chapman\& Hall; 1993. Agresti A. Categorical data analysis. 2nd edn. New Jersey: John Wiley\& sons.

19. Kleinbaum D, Kupper L, Muller K, Nizam A (1998) Applied Regression Analysis and Otherb Multivarable Methods. Pacific Grove: Duxbury Press.

20. Dagenais S, Haldeman S (2012) Evidence-Based Mangement of Low Back Pain. St Louis Missouri: Elsevier Mosby.

21. Bringsli M, Berntzen A, Olsen DB, Hestbæk L, Leboeuf-Yde C (2012) The Nordic Maintenance Care Program: Maintenance care - what happens during the consultation? Observations and patient questionnaires. Chiropr Man Ther 20: 25 .

22. Senstad O, Leboeuf-Yde C, Borchgrevink CF (1996) Side-effects of chiropractic spinal manipulation: types frequency, discomfort and course. Scand J Prim Health Care 14: 50-53.

23. Dewi S, Aune T, Aasen JB, Smith AJ, Larsen S (2014) The development of Response Surface Pathway design in toxicity study. BMC Pharmacol Toxicol 15:18.

24. Dewi S, Kristiansen V, Lindæker-Jensen S, Larsen S (2014) Between- and within- patient n-level response surface pathway design in dose-finding studies. Open Access J Clin Trials 6: 63-74. 